\title{
A cidade simbólica: inscrições no tempo e no espaço
}

Regina Beatriz Guimarães Neto*

\begin{abstract}
Resumo: A proposta central deste artigo é analisar as representações sobre as cidades que irrompem nos fragmentos dos diversos relatos e registros dos seus habitantes. Nos "relatos de espaço", homens e mulheres codificam e distinguem simbolicamente espaços e lugares, imbricados às várias temporalidades. Reunidos em uma trama narrativa, sinalizam práticas culturais, organizadoras dos espaços e constitutivas das configurações urbanas.

Abstract: The central proposal of this article is to analyze the representations about the cities that emerge in the fragments of several reports and records of their inhabitants. In the "reports of the space" men and women codify and distinguish symbolically spaces and places, which are connected to several temporal dimensions. Gathered in a narrative plot, they show cultural practices that are organizers of the spaces and constitutive of the urban configurations.
\end{abstract}

Palavras-chave: Cidade. História. Memória.

Key words: City. History. Memory.

\section{A cidade simbólica: inscrições no tempo e no espaço}

Questões que interrogam o passado das cidades fascinam sobretudo pelos caminhos labirínticos que indicam ou apenas se insinuam nas paisagens que emergem das sombras das memórias, ora em imagens precisas, ora fluidas, ora grotescas, ora diáfanas. Como falar de uma cidade? Como abordar o seu passado e a construção de sua memória? As descrições que se atêm aos planos urbanos, fixando-se nas projeções de ruas e construções de casas, e mesmo ao número de habitantes e tantas outras indicações des-

Professora Doutora do Departamento de História - Programa de Pós-Graduação da Universidade Federal de Mato Grosso.

Estudos Ibero-Americanos. PUCRS, v. XXXII, n. 1, p. 143-155, junho 2006 
providas de suas referências simbólicas, deixam escapar o universo das experiências culturais, "sem o que - diria Machado de Assis - tudo é calado e incolor" (Dom Casmurro). Localizações espaciais diversas, quando vistas de outro ângulo, podem emitir diferentes signos que, implicados e enredados nos objetos e pessoas, impregnam com sua atmosfera poética as ruas, os bairros e as praças, e mesmo a forma dos casarios, absorvendo nossos olhares, significando e entrelaçando vivências e imaginação. Falar de uma cidade, inspirando-nos em autores como James Joyce, ${ }^{1}$ Marcel Proust ${ }^{2}$ e Machado de Assis, ${ }^{3}$ é, sobretudo, narrar histórias partidas, em que os diversos fragmentos da vida de seus habitantes aparecem como inscrições do tempo nos espaços vividos.

E, ademais, a memória - segundo Deleuze - não é um fim em si mesma, mas um caminho de aprendizagem, descobrindo ou revelando objetos e pessoas que não possuem a chave do segredo de suas existências, mas remetem a uma rede de relações culturais, produtoras de signos que dão sentido ao mundo. ${ }^{4}$ Nessa leitura, aponta-se uma coexistência virtual do passado com o presente: "esse passado não representa alguma coisa que foi, mas simplesmente alguma coisa que é e coexiste consigo mesma como presente; que o passado não pode se conservar em outra coisa que não nele mesmo, porque é em si, sobrevive e se conserva em si" - essas são as célebres teses de Matière et mémoire. ${ }^{5}$ Este ser em si do passado, Bergson o chamava de virtual. Proust faz o mesmo quando fala dos estados induzidos pelos signos da memória: "Reais sem serem atuais, ideais sem serem abstratos". 6 A relação entre dois momentos ou duas sensações pode se dar ou ser ativada pela qualidade comum que envolve o atual e o antigo, "tornando o antigo contexto inseparável da sensação presente". Contudo, há que se considerar, de acordo com Deleuze, que o importante não é a semelhança, nem a identidade entre os dois momentos, passado e presente, mas a coexistência que "implica uma relação com alguma coisa diferente". É essa possibilidade que impede a mera repetição,

1 Cf., JOYCE, James. Dublinenses. 4. ed. Rio de Janeiro: Civilização Brasileira, 1992, em especial o conto "Os mortos".

2 Cf. PROUST, Marcel. No caminho de Swann. São Paulo: Globo, 1990.

3 Destaco os contos do autor em que a cidade do Rio de Janeiro emerge em cada esquina dobrada, cada rua percorrida, em cada morro e mar avistados. Sobretudo aqueles reunidos em "Várias histórias", "Papéis avulsos" e "Páginas recolhidas". In: Obra completaI (organizada por Afrânio Coutinho). Rio de Janeiro: Nova Aguilar, 2004. v. 2.

4 Cf., DELEUZE, Gilles. Proust e os signos. Rio de Janeiro: Forense-Universitária, 1987.

5 BERGSON, Henri. Matéria e memória. São Paulo: Martins Fontes, 1990.

6 DELEUZE, op. cit., p. 58-59. 
fazendo ressurgir o novo na coexistência virtual do antigo com o atual. Pode-se pensar, nessa perspectiva, em invenção, em (re)descobertas, nas memórias e relatos que emergem das cidades, associadas ao ponto de vista de que a "exploração" da memória só interessa pelo processo de aprendizagem que desencadeia, através do sistema de signos, em busca do "sentido" - sempre plural implicado, envolvido nas experiências da vida.

Mediante essas considerações, refletindo desde já sobre as determinações que se estabelecem nas análises sobre memória, tornase fundamental insistir num ponto crucial para a história: o discurso produzido no presente não se apodera diretamente dos eventos que já ocorreram, mas sim, passa por mediações fundamentais tanto pela complexidade dos atos de memória quanto pelas regras da escrita - ao apresentar o passado. Certamente, ao constituir a memória passada, os historiadores submetem-se às injunções da linguagem na construção do texto. Tanto a narrativa de ficção quanto o discurso historiográfico - literatura e história - compartilham as artes de fabricação dos enredos, compondo histórias segundo jogos de linguagem. Contudo, tais observações não implicam desconhecer a especificidade da história, que atualiza o vivido segundo regras autorizadas no âmbito da disciplina, articulando os limites ou recortes que indicam as diferentes temporalidades e espacialidades apresentadas no discurso sobre o passado. ${ }^{7}$

A historiografia, seguindo a trilha de Michel de Certeau, trabalha os relatos sobre os acontecimentos passados como fabricação, entendendo-se o discurso sobre o passado como resultado de operações que modificam os "dados", vestígios e fontes pesquisadas. Longe de aceitar um "passado desvendado" em seu texto, o historiador o constitui por meio da prática da pesquisa e da escrita, inteiramente comprometidas com as instituições de saber do tempo presente. ${ }^{8}$ Nessa trilha, a prática historiográfica atual procura romper, por um lado, com as barreiras erigidas pelos critérios de cientificidade que o modelo positivista apregoa, impondo o reinado do documento escrito e oficial; por outro, afasta-se cada vez mais da idéia de que a produção do conhecimento histórico prescinde de uma estrutura narrativa, em razão da premissa de que para ser ciência ou ter um estatuto científico, a história deve fun-

7 Cf., CERTEAU, Michel de. A escrita da história. Rio de Janeiro: Forense Universitária, 1982; CHARTIER, Roger. À beira da falésia. A História entre certezas e inquietude. Porto Alegre: Ed. UFRGS, 2002, em especial "A história entre narrativa e conhecimento".

8 Cf., CERTEAU, op. cit. 
cionar segundo leis, cifras, série de números, controladas por meios técnicos. ${ }^{9}$

Reconhecer o importante papel que desempenham as figuras de linguagem e os procedimentos da narração, na produção do texto historiográfico, leva-nos a questionar o conhecimento histórico sob novas bases e a assinalar a decisiva contribuição de autores como Paul Veyne. Para este, os acontecimentos só adquirem valor histórico quando fluem na narrativa, isto é, quando aparecem construídos na trama tecida pelo historiador, integrando acasos, situações, eventos variados e dispersos, recusando o aparato da "ciência do concreto", a favor da lógica do provável. ${ }^{10}$ Neste campo da incerteza, só há história quando acontecimentos - fragmentários - adquirem significação inteligível na conformação do enredo, passando a história a ser construção e a depender da configuração narrativa. ${ }^{11} \mathrm{O}$ destaque a esta questão ganha ainda maior relevo nas análises desenvolvidas por Paul Ricoeur:

a justeza da interpretação narrativa consiste em ter percebido perfeitamente nela que a qualidade propriamente histórica da história só é preservada pelos laços, por mais tênues e dissimulados que sejam, que continuam a vincular a explicação histórica à compreensão narrativa, a despeito da ruptura epistemológica que dissocia a primeira da segunda. ${ }^{12}$

Nas longas páginas em que se dedica a construir sua tese sobre o estatuto narrativo da história, Ricoeur afirma que a história menos descritiva, e, por isso, mais ligada à análise das estruturas, que se apóia em números, aproximações e determinações quantitativas, mesmo ela, também pertence ao campo da narrativa, ou seja, utiliza as figuras de linguagem e os modos de proceder da composição narrativa. ${ }^{13}$

Neste ponto, recoloca-se a importância da dimensão poética do discurso, que não deve ser vista contrapondo-se às regras da escrita da história, ou como óbice ao rigor metodológico que se exige da disciplina. Pelo contrário, na construção da trama narrativa, "o discurso poético traz à linguagem aspectos, qualidades, valores da realidade, que não têm acesso à linguagem diretamente

9 Cf., LE GOFF, Jacques. A história nova. São Paulo: Martins Fontes, 1990. Ver a crítica em RICOEUR, Paul. Tempo e narrativa. vol. I. Campinas: Papirus, 1994, em "O eclipse da narrativa".

10 Cf., VEYNE, Paul. Como se escreve a história. Lisboa: Edições 70, 1971.

11 Cf., ibidem.

12 RICOEUR, op. cit.

13 Consultar especialmente a segunda parte de RICOEUR, 1994. 
descritiva e que só podem ser ditos em favor do jogo complexo entre a enunciação metafórica e a transgressão regrada das significações usuais de nossas palavras". ${ }^{14}$ Daí se depreende que o discurso poético é produtor de inteligibilidade, de especificidades e diferenças, vital para se alcançar os efeitos de refiguração do passado, vinculando a explicação histórica à compreensão narrativa. É por isso, também, que construir narrativas acerca dos eventos passados não é copiar, imitar "tal como foi", 15 mas um ato criativo, produtor de efeitos de encenação, que reúne e configura os múltiplos eventos passados na tessitura das tramas, conferindo-lhes inteligibilidade. Em última instância, cria a vida no território dos mortos.

\section{A paisagem da pesquisa}

Em face das considerações apresentadas, volto sempre à mesma indagação quando tenho como foco o estudo de uma cidade. Como apresentar um texto que problematiza a memória social de uma cidade? O que é uma cidade? De que matéria é feita? Que signos emitem o seu mundo em constante movimento? Este desafio se colocou a mim quando elegi como tema de minhas pesquisas algumas cidades que surgiram na esfera dos chamados "projetos de colonização", particularmente aqueles localizados no norte do Estado de Mato Grosso, território amazônico, ${ }^{16}$ a partir da década de 70 do século $X X$.

14 RICOEUR, op. cit., p. 11.

15 Deleuze faz críticas contundentes a uma literatura que chama "objetivista": "É decepcionante, por natureza, uma literatura que interpreta os signos relacionando-os com objetos designáveis (observação e descrição), que se cerca de garantias pseudoobjetivas do testemunho e da comunicação (conversa, pesquisa), que confunde o sentido com significações inteligíveis, explícitas e formuladas (grandes temas)" (DELEUZE, op. cit., p. 33).

16 Segundo a divisão regional do País, a Amazônia compreende a Região Norte (os estados de Rondônia, Acre, Amazonas, Roraima, Amapá, Pará e Tocantins) e parte da Região Centro-Oeste (o estado de Mato Grosso). A soma das áreas destes estados é de 4,7 milhões de quilômetros quadrados. A outra referência para o território amazônico, que o define como Amazônia Legal (denominação que aparece com a criação do Plano de Valorização da Amazônia, em 1953), inclui o oeste do Maranhão. Contudo, ao fazer menção ao território amazônico, as análises desenvolvidas neste artigo têm em vista apreender a constituição do território a partir das práticas sociais, permitindo pensar o território no seu papel ativo, compreendendo a sua dimensão simbólica. A respeito da noção de região, cf., BOURDIEU, Pierre. O poder simbólico. Lisboa/Rio de Janeiro: Bertrand/Difel, 2000 (especificamente "A identidade e a representação. Elementos para uma reflexão crítica sobre a idéia de região", p. 107132); ALMEIDA, Alfredo Wagner B. de. Carajás: a guerra dos mapas. Belém: Seminário 
Estes projetos, dos quais resultarão mais de cem municípios novos só no estado de Mato Grosso, entre meados da década de 1970 e a década de 1990, são analisados como parte da estratégia política dos governos militares de controle dos conflitos agrários no Sul, Sudeste e Nordeste. Apresentados pelo discurso oficial como "distribuição racional de população" e ocupação dos "espaços vazios" da Amazônia, operaram de fato como impedimento do livre acesso - ou acesso regulado - de trabalhadores sem terra e pequenos proprietários às terras devolutas do Estado. As medidas governamentais que estimularam a ocupação dirigida à Amazônia, em parceria com a iniciativa privada, foram implementadas no âmbito dos planos nacionais que reestruturaram novas práticas de domínio político para o território nacional. Os pólos de desenvolvimento econômico, as políticas de incentivos fiscais e a implementação de grandes eixos rodoviários na região amazônica encontram-se entre as estratégias mais importantes para a exploração econômica dos "novos espaços".

A partir da conformação espacial da colonização na década de 1970, desenvolve-se uma rede urbana que se estende ao longo dos grandes eixos rodoviários, provocando uma reterritorialização dos "novos" e "velhos" espaços, com implicações políticas, econômicas e culturais duradouras. ${ }^{17}$ Os chamados núcleos de colonização constituir-se-ão em instrumentos políticos de controle não apenas do acesso à terra, mas ainda da formação de um mercado de mãode-obra, recebendo vultosos incentivos financeiros do governo brasileiro, patrocinando a iniciativa privada. Resta destacar que a colonização como narrativa que participa da elaboração do mito do Eldorado, indicado como a terra da abundância e da fartura, é reveladora dessas práticas políticas. Nesse sentido, torna-se necessário chamar a atenção para a positividade que adquire o termo colonização, adotado pelos meios oficiais e empresas que atuaram em grandes áreas de terras dos estados que compõem a Amazônia.

Consulta, Supercores, 1995 (consultar especialmente "Introdução", p. 35-48). Cf. a concepção de território a partir de seus usos em SANTOS, Milton. A natureza do espaço. Técnica e tempo. Razão e emoção. São Paulo: Hucitec, 1996; e, do mesmo autor, O Brasil: território e sociedade no início do século XXI. Rio de Janeiro: Record, 2001.

17 Ver sobre o tema da colonização recente em Mato Grosso: GUIMARÃES NETO, Regina Beatriz. A lenda do ouro verde. Política de Colonização no Brasil contemporâneo. Cuiabá: Ed. UNICEN/Apoio UNESCO, 2002; OLIVEIRA, João Mariano. A esperança vem na frente - o caso SINOP. São Paulo, 1982 (dissertação em História - Faculdade de Filosofia Letras e Ciências Humanas, Universidade de São Paulo; SOUZA, Edison Antônio de. Sinop: história, imagens e relatos. Um estudo sobre a colonização. Cuiabá, 2001 (dissertação em História - Instituto de Ciências Humanas e Sociais, Universidade Federal de Mato Grosso); SANTOS, A natureza do espaço. 
Reflete o poder de um discurso construído para mobilizar e justificar a expropriação de bens de produção de diversos segmentos de pequenos produtores rurais do Brasil; abonar a instauração de um grande mercado de terras, pela iniciativa privada, controlando a distribuição, o acesso e a posse das áreas, além de selecionar as demandas de trabalhadores rurais; instituir práticas de segregação social e exploração do trabalho (muitas vezes no nível da "escravidão por dívida"), em nome do desenvolvimento e progresso dos novos núcleos urbanos.

Nesse sentido, é que as novas cidades que surgiram, no território amazônico, articuladas a uma grande rede viária e ao mercado capitalista, não são resultados "naturais" do movimento de deslocamento dos diversos grupos sociais que para lá se dirigiram, denominado de processo migratório. Relacionam-se muito mais a um conjunto de práticas organizadoras de políticas de controle e monopólio da exploração da riqueza por parte dos grandes empresários e proprietários. As cidades trazem inscritas em seu espaço as práticas sociais de segregação, de violência e de cerceamento dos direitos civis, que não podem ocultar. ${ }^{18}$ Mas não só isto, manifestam, a todo o momento, práticas de resistência, atuações de organizações civis e religiosas, demarcando um território de conflito.

A proposta central em meus estudos é analisar as representações sobre as cidades que irrompem nos fragmentos dos diversos relatos e registros dos seus habitantes. São apreendidos acontecimentos cotidianos esmiuçados, verdadeiras bricolagens de histórias ocorridas no passado, coexistindo com as histórias presentes, compondo um vasto conjunto de narrativas. O passo mais importante, ou melhor, o foco prioritário das análises sobre as representações recai sobre os "relatos de espaço", em que homens e mulheres codificam, marcam e distinguem simbolicamente espaços e lugares. Mas eles, fundamentalmente, aparecem imbricados a várias temporalidades, havendo, um movimento - uma junção entre espaço e tempo, onde ocorre o encadeamento das histórias. Estas atuam como indicadores de uma rede de práticas culturais, organizadoras dos espaços e constitutivas das novas configurações urbanas.

O interesse nestes estudos se volta para pensar mais detidamente como a memória se entrelaça aos espaços habitados, demarcados e classificados num intenso processo de desterritorialização

18 Cf. GUIMARÃES NETO, Regina Beatriz. Vira mundo, vira mundo: trajetórias nômades. As cidades na Amazônia. Projeto História, São Paulo, PUC, nº 27, p. 49-69, 2003. 
e reterritorializações. Desse modo, a narrativa está voltada para a emergência de uma trama de histórias, relacionada e analisada à constituição de uma rede cartográfica das trajetórias sociais daqueles que se deslocaram para os diversos núcleos de "colonização", produzida por meio dos relatos que desenham um território ativo como resultado das práticas culturais. Em face dessas experiências, as cidades são focalizadas na configuração espacial e cultural da Amazônia, analisando as práticas de espaço dos seus habitantes e sua relação com a produção da memória histórica. ${ }^{19}$

\section{Narrativas de espaço}

Este texto, ao destacar as narrativas dos moradores, reflete sobre o papel ativo dos relatos na construção da memória das cidades, instituindo recortes espaços-temporais que compõem o seu passado e produzem efeitos de verdade e realidade. A tese proposta é que as narrativas assinalam as práticas de espaço que se tornam referências fundamentais, indicativas para a produção discursiva do passado, entendendo que todo relato de memória é um relato de percurso. Dessa forma, o ato de contar é criador, ele "dá a ver", desenhando os espaços habitados, do mesmo modo que as imagens de ruas, casas, praças, compostas em cenas, geram quadros narrativos: contam as histórias das cidades. Os espaços, assim, longe de serem homogêneos e vazios, aparecem impregnados de significados simbólicos, seja no ambiente urbano - no bairro, na rua ou no interior das habitações -, seja numa rede de relações exteriores que estabelecem com outros territórios (étnicos, culturais, políticos) e os situam numa dada configuração de poder. Nesse sentido, os espaços não são anteriores às práticas que os produzem; pelo contrário, são elas, as práticas, que lhes conferem significados. ${ }^{20}$

19 Vila Rica, no extremo norte, e Confresa foram cidades projetadas pela iniciativa privada, embora esta última tenha sido sistematicamente ocupada por trabalhadores pobres que, ao não poderem comprar a terra, utilizaram inúmeras estratégias de resistência, resultando em vários conflitos armados na região, desmontando o planejamento urbano inicial; já a cidade de Juína, localizada a noroeste do estado, foi planejada pela iniciativa pública, coordenada pela CODEMAT (Companhia de Desenvolvimento do Estado de Mato Grosso). As áreas dessas cidades, compreendendo os respectivos municípios, foram abertas usurpando o direito de várias etnias indígenas e pequenos produtores que tinham a posse da terra, mas não a propriedade legal.

20 Cf. especialmente, CERTEAU, Michel de. A invenção do cotidiano. Artes de fazer. 5. ed. Petrópolis: 1994, v. 1.; SERRES, Michel. Atlas. Madrid: Cátedra, 1995. 
Nesse âmbito, uma geografia de cunho antropológico tem o primado sobre a geografia física, possibilitando perceber que os moradores, por meio do trabalho poético da memória, subordinam a configuração gráfica urbana a uma representação em que a vida, nos detalhes, nas "artes do fazer", é recoberta em seus múltiplos significados culturais. Há uma justaposição ou combinação de imagens de lugares, em que a capacidade de inverter a geografia convencional em geografia imaginada, associada ao tempo, tornase uma prática discursiva. Por isso mesmo, as territorialidades assinaladas aparecem imbricadas a várias temporalidades, havendo uma junção vital entre espaço e tempo, que oferece suporte textual ao encadeamento das histórias. Isto é, o "tempo daquela época" aparece indicado por meio de palavras como "aqui", "lá", e "acolá". São como peças retiradas da topografia da cidade, primeiramente numa representação mimética para, em seguida, dar lugar aos acontecimentos, envolvidos nas lembranças que conformam as experiências passadas e refiguram efetivamente os espaços na memória. No relato de uma residente de Juína, relembrando a ocasião em que os primeiros moradores chegam à cidade, tem-se um exemplo dessa estreita ligação entre os advérbios de lugar e as indicações temporais:

Ali, onde está o Cidetran hoje, tinha um pé de coco, daqui de casa a gente via os coco caírem, os pedreiros falavam assim: aqueles cocos caíram, os bichinhos estão lá comendo, nós vamos lá buscar, nós vamos lá e você coloca a água para ferver. Antes de a água ferver a gente ouvia o tiro. Porque era só atravessar a rua e chegava ali no mato. Ali! Era mato em pé! Eu vi derrubar aquele mato, eu vi as árvores caindo... Os pedreiros matavam bicho no mato todo dia para fazer aquelas paneladas de carne. Era a maior fartura! Era cotia, era paca, era veado, era anta... (relato de dona Aparecida Dias, setembro de 2000).

Mais do que descrições que reforçam a representação mítica da abundância da "nova terra", com uma fauna e flora exuberantes, trata-se de uma representação da cidade e do território que associa elementos da cartografia convencional com os das experiências culturais, oferecendo uma outra compreensão, para além dos discursos dos planejadores e administradores urbanos, instituidores de uma racionalidade técnica. Já um outro morador, agora da cidade de Confresa, aponta a constituição do território urbano mediante práticas sociais que desmontam o quadro planejado dessas "cidades da colonização": 
Ali não era para ser cidade, era uma reserva de mata que deveria permanecer, mas aí inventaram de fazer uma invasão. A mata que era reserva foi toda para o beleléu, aqui tinha gente de todos os lugares, gente de todo jeito... (senhor V. C. C., entrevista realizada por Maria Figueira Cerqueira, em 4 de janeiro de 2001).

E podemos completar com as palavras sábias de Maria Figueira Cerqueira: "No papel está o mapa do projeto de colonização, mas o povo fez outro por conta própria".

Trabalhadores sem terra e mesmo pequenos proprietários denominados de colonos invertem as programações e previsões das empresas colonizadoras. Por meio de ações coletivas e de enfrentamentos conflituosos, provocam mudanças de áreas planejadas para determinados fins, com funções diferentes do que estava previsto. As próprias empresas e depois os poderes públicos instalados criam "bairros novos", a fim de controlar e administrar a chegada de diversos trabalhadores pobres, como na cidade de Vila Rica, onde se organiza a mudança da cadeia pública, do cemitério e da zona de meretrício para o bairro Vila Nova, destinado a pessoas de comprovada baixa renda e com maior número de dependentes (Lei municipal no 196/93, de 9/12/1993), extinguindo o popular "Pau Seco", a primeira área de meretrício, que ocupava um espaço considerado nobre para a cidade.

Contudo, mesmo diante deste quadro, o discurso que elabora a imagem da cidade em seus movimentos iniciais representa a força do progresso. Caracterizando os momentos iniciais, ora no movimento de chegada de homens e mulheres de todas as regiões do Brasil, ora no aparecimento das casas, ora nas transformações das paisagens, o próprio tempo se desdobra e se multiplica desvendando, inventando e desenhando os locais da cidade que encena os contrastes:

A cidade passa a crescer "democraticamente" e as condições de vida continuam muito precárias, tanto para o centro da cidade, como para os arrabaldes. Pois, a poeira toma conta, dando uma pintura homogênea à jovem cidade. É um contraste natural; época de seca, o poeirão cobre; época das chuvas, os atoleiros engolem. São imagens apreciadas ainda hoje (Nilcéia Terezinha Dal Bó, Juína, 2001).

A passagem sugere que as marcas insistem em permanecer, congeladas em cristais de lembranças, como a recordar as dificuldades enfrentadas pelas famílias de colonos e demais trabalhadores que construíram as novas cidades. Pode-se observar que os diversos narradores, por meio das conversas e dos relatos de memórias, assinalam o trabalho do tempo nos espaços vividos e 
apontam as suas transformações materiais e culturais. Nesse ambiente de constantes mudanças, que recebe pessoas de vários lugares do país, os encontros entre grupos sociais com práticas culturais, hábitos e costumes diferentes criam situações inusitadas, configurando-se um território de migrantes, marcado pelos contrastes das paisagens geográficas e culturais, fazendo a experiência e a memória das novas cidades.

Diante disso, as narrativas dos habitantes que descrevem lugares, passagens e itinerários - relatos cotidianos - compõem um grande corpus documental. Um trabalho de levantamento de fontes que utiliza memórias orais e escritas, assim como matérias da imprensa (local e nacional) e registros policiais, constituindo um conjunto de narrativas que compõem histórias e cenários urbanos entrelaçados. ${ }^{21}$ Torna-se importante perceber como a memória narrada apresenta indícios de uma rede de relações sociais que se estrutura num tempo e espaço próprios, considerando os interesses dos diversos grupos e as estratégias individuais e coletivas. Essa incursão pelos vários registros orais e escritos, vistos como fragmentos de trajetórias sociais, que alteram, deslocam e constituem os espaços, provocam a irrupção de outras leituras que configuram as histórias das cidades.

Tomando por base os vários relatos como narrativas da cidade, dois aspectos principais direcionam as reflexões metodológicas: a análise do tempo denso das memórias, constituído em várias temporalidades, que se estendem e se envolvem umas às outras; e, simultaneamente, os relatos de percurso que circunscrevem os espaços habitados tecem os lugares através dos itinerários dos seus moradores - impressos nos traços da memória -, desenhando a diversidade histórica e cultural da vida urbana. Dois caminhos abertos que se interconectam e dão sentido um ao outro, fundamentais para dar maior base de apoio teórico aos resultados das investigações. Primeiramente, sem postular ordem hierárquica, as reflexões direcionam as análises sobre tempo e narrativa. Neste aspecto, as narrativas, como obra da imaginação criativa, são estudadas segundo as representações do passado que efetuam, trazendo as marcas das experiências temporais, que assinalam o desen-

21 O trabalho de entrevistas foi realizado por mim e por grupos de alunos, sob minha orientação, dos cursos de graduação em História da Universidade Federal de Mato Grosso, na cidade de Juína (MT), e da Universidade Estadual de Mato Grosso, na cidade de Luciara (que agregava as pesquisas sobre as cidades de Confresa e Vila Rica). Ao todo, foram elaboradas 30 monografias, além de 14 entrevistas com trabalhadores temporários (que se encontram no acervo do Programa de Pós-Graduação da Universidade Federal de Mato Grosso). 
volvimento das ações humanas no tempo histórico. Destaca-se, neste caso, a reciprocidade entre narratividade e temporalidade, tão cara à análise de Paul Ricoeur, desenvolvida em Tempo e narrativa. ${ }^{22}$ Segundo este autor, "o tempo torna-se tempo humano na medida em que está articulado de modo narrativo; em compensação, a narrativa é significativa na medida em que esboça os traços da experiência temporal". ${ }^{23}$ Pelo fato de serem narrados, os acontecimentos encontram-se vinculados à compreensão narrativa, $\mathrm{O}$ que nos leva a procurar melhor entender "a operação que unifica numa ação inteira e completa a diversidade constituída pelas circunstâncias, os objetivos e os meios, as iniciativas e as interações, as mudanças de sorte e todas as conseqüências não desejadas surgidas da ação humana". ${ }^{24}$ Operação de síntese, portanto, a narrativa reúne, numa história completa, de forma alguma inocente, os acontecimentos dispersos e vários tipos de ações, planejadas e inesperadas, dando a eles significados precisos. Logo, as histórias relatadas, utilizando as figuras e os procedimentos da narração, representam o tempo vivido e nos conduzem ao jogo das experiências sociais. Tendo em vista essas considerações, compreendese a importância do ato de narrar como prática discursiva que tem um papel crucial na produção da memória das cidades, relevando as narrativas que ordenam e dão inteligibilidade ao mundo vivido.

É neste ponto que a segunda ordem de reflexão torna-se central, a que diz respeito às relações entre narrativa e espaço. Compreendendo-se que, se as narrativas descrevem e refiguram os espaços das cidades em sua vivência cotidiana, tensa, fragmentada e descontínua, elas, fundamentalmente, participam da criação das cidades. Os espaços urbanos que emergem das narrativas surgem, assim, da forma como os relatos articulam os eventos passados e os refiguram no espaço, instituindo temporalidades e espacialidades produtoras de uma realidade. Paul Ricoeur, em obra mais recente, La mémoire, l'histoire, l'oubli, sublinha que uma cidade confronta no mesmo espaço temporalidades diversas, trazendo inscrita e sedimentada uma história multicultural, que pode, ao mesmo tempo, se dar a ver e a ler. ${ }^{25} \mathrm{O}$ tempo narrado e as práticas de percurso, nessa perspectiva, ganham traços visíveis - coexistindo com os invisíveis -, quando articulados de forma narrativa; adquirem

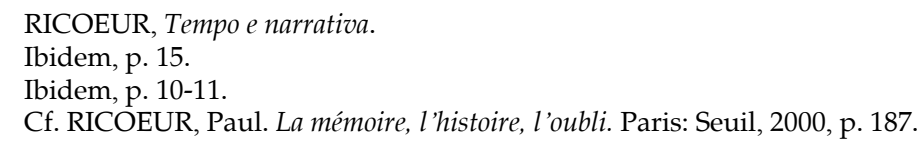


legibilidade no texto da cidade. Pode-se inferir, deste processo social, a própria invenção das cidades.

Assim, as narrativas tecem a memória por meio das linhas do tempo como inscrições que deixam suas marcas nos espaços vividos e que contêm, como os sinais das mãos, o mundo dos constantes deslocamentos territoriais de homens e mulheres pobres nas cidades que se localizam na Amazônia. Não há uma totalidade prévia ou muito menos um quadro único, porque os relatos, longe de fixarem espaços e lugares, os recriam culturalmente. Mesmo considerando as mesmas cidades, os contextos são sempre múltiplos, movimentam-se pela variedade das experiências narradas, acontecimentos imprevistos e, sobretudo, pontos de vista indicados. Assim, os relatos podem ser reveladores de personagens diversas e "a história narrada cria um espaço de ficção". ${ }^{26}$

26 CERTEAU, op. cit., p. 153. 